\title{
Study of ss-DNA Adsorption and Nano-mechanical Properties on Mica Substrate with Surface Forces Apparatus
}

\author{
Gui-Bin Shen ${ }^{1,2}$, Ya-Jing Kan ${ }^{1,2^{*}}$, Min-Hua Chen ${ }^{2}$ and Yun-Fei Chen ${ }^{1,2}$
}

\begin{abstract}
Many DNA-based devices need to build stable and controllable DNA films on surfaces. However, the most commonly used method of film characterization, namely, the probe-like microscopes which may destroy the sample and substrate. Surface Forces Apparatus (SFA) technique, specializing in surface interaction studies, is introduced to investigate the effects of DNA concentration on the formation of single-stranded DNA (ss-DNA) film. The result demonstrates that $50 \mathrm{ng} / \mu \mathrm{L}$ is the lowest concentration that ss-DNA construct a dense layer on mica. Besides, it is also indicated that at different DNA concentrations, ss-DNA exhibit diverse morphology: lying flat on surface at $50 \mathrm{ng} / \mu \mathrm{L}$ while forming bilayer or cross-link at $100 \mathrm{ng} / \mu \mathrm{L}$, and these ss-DNA structures are stable enough due to the repeatability even under the load of $15 \mathrm{mN} / \mathrm{m}$. At the same time, an obvious adhesion force is measured: $-6.5 \mathrm{mN} / \mathrm{m}$ at $50 \mathrm{ng}$ / $\mu \mathrm{L}$ and $-5.3 \mathrm{mN} / \mathrm{m}$ at $100 \mathrm{ng} / \mu \mathrm{L}$, respectively, which is attributed to the ion-correlation effect. Moreover, the atomic force microscopy (AFM) images reveal the entire surface is covered with wormlike ss-DNA and the measured surface roughness $(1.8 \pm 0.2 \mathrm{~nm})$ also matches well with the film thickness by SFA. The desorption behaviors of ss-DNA layer from mica surface occur by adding sodium salt into gap buffer, which is mainly ascribed to the decreased ion-ion correlation force. This paper employing SFA and AFM techniques to characterize the DNA film with flexibility and stable mechanical ability achieved by ion bridging method, is helpful to fabricate the DNA-based devices in nanoscale.
\end{abstract}

Keywords: Single-stranded DNA, Adsorption, Nano-mechanical properties, lon-correlation effect, Surface forces apparatus

\section{Introduction}

DNA is a potentially valuable biomaterial since DNA nanotechnology can produce DNA-based thin film on inorganic surface to construct flexible nanostructures with ability of programmable and specific recognition, i.e., selectivity and sensitivity $[1,2]$. Based on these film and nanostructure, many DNA-based nanodevices can be fabricated, such as biosensors [3-5], microfluidic devices [6], DNA chips [7], micro arrays [8, 9], disease-diagnosis [8-10]. The fabrication of these devices depends not only on their chemical and physical properties, but also on the conformation, load-carrying ability and type of DNA.

\footnotetext{
*Correspondence: yajingkan@seu.edu.cn

1 Jiangsu Key Laboratory for Design and Manufacture of Micro-Nano Biomedical Instruments, Southeast University, Nanjing 211189, China Full list of author information is available at the end of the article
}

Hence, it is greatly significant to explore the adsorption and nano-mechanical properties of DNA at solid/liquid interface.

The DNA species used in many investigations are long and giant double-stranded DNA (dsDNA) [11-13], and little attention has been paid to ss-DNA absorption on various substrates. Adamcike et al. [14] using AFM, showed ss-DNA on mica have compact structures with lumps, loops and super twisting, while on highly oriented pyrolytic graphite (HOPG), adopt a conformation without secondary structures. However, more mechanical properties of ss-DNA adsorbing on solid substrate are expecting further study.

Immobilization of DNA on substrate surface has been investigated by many techniques, such as atomic force microscopy (AFM) [15-17], scanning tunnel microscope (STM) [18, 19], and scanning electron microscope 
(SEM) [20]. Among all these ways, AFM is the most commonly used for studying DNA geometry. For instance, Cervantes et al. [21] compared two methods of binding $\lambda$-DNA on mica by AFM, and found distinct DNA networks using deposition buffers, but uniform coverage of isolated $\lambda$-DNA in spin-coating due to a particular force. However, the detector with micro-size probe may be inevitable to disrupt sample geometry [22], affecting the accuracy of DNA characterization. Other instruments can also be used to explore DNA adsorption. Cao et al. [20] reported an oriented chiral DNA film by SEM, and proposed highly ordered DNA film was aligned by mica crystal with the guiding effect of $\mathrm{Mg}^{2+}$. However, the high-energy electron beam of SEM may locally heat biological sample, and the vacuum environment also limits its application.

In sum, the morphology and dynamic changes of DNA on various substrates have been described by AFM, SEM, STM, but many probe-like microscopes may destroy the geometry of sample and substrate during test. In this paper, a surface forces apparatus (SFA), which specializes in measuring the interaction between two surfaces in solutions, is mainly utilized to discuss the adsorption and load-carrying abilities of ss-DNA on mica. Compared with other techniques, SFA utilizing the sample surface with millimeter-curvature is more ideal to study the adsorption mechanisms of the nano-film at solid/ liquid interface. More specifically, it is capable of characterizing the mechanical and adhesive properties of biomaterials confined between two surfaces, and getting the absolute thickness of adsorbed film. Besides, SFA can also describe the density of adsorbed films derived from the refractive index of the medium confined between two surfaces [23].

Flat crystalline and large-scale substrates are needed in SFA and AFM. Muscovite mica is an ideal inorganic substrate due to its relatively large atomically flat areas and ease of preparation [24], which is negatively charged in solutions for the release of $\mathrm{K}^{+}$[25]. Similar to mica, DNA is also negatively charged due to its phosphate backbone [13], leading to an electrostatic repulsion barrier energy between DNA and mica. Therefore, the substrate requires to be treated in advance in order to tightly fix DNA on mica. Generally, the mica surface is pretreated with divalent or multivalent cations (such as $\mathrm{Ni}^{2+}, \mathrm{Co}^{2+}$, spermidine) $[11,13,26,27]$, bridging DNA's phosphate groups and mica surface. Mica functionalization with silanes is to invert the surface charge to induce DNA binding [17, 28], which may change the DNA conformation and rigidity significantly [29]. In addition, mica surface can also be modified via Langmuir-Blodgett (LB) film technique, to directly measure the interaction between DNA bases [30].
Modification mica with divalent salts to adsorb DNA is more simple and thus practicable. However, the mechanism of divalent-ion-mediated DNA adsorption is still in dispute. Hansma et al. [31] initially ascribed that divalent cations penetrate into the "cavities" on mica surface and react with the interfacial hydroxyl groups. However, the subsequent works proposed that DNA adsorption is dominated by the cooperative effect driving condensation with divalent cations, subsequently reacting with surface groups [32]. More recently, there are several researches considering the binding due to the ion-correlation effect [12, 13, 33]. Anyway, the real binding mechanism still requires us to make it clearer. Besides, it is interesting to indicate that some transitional metals cations $\left(\mathrm{Ni}^{2+}, \mathrm{Co}^{2+}, \mathrm{Zn}^{2+}\right)$ are effective in DNA adsorption, whereas others $\left(\mathrm{Mn}^{2+}\right.$, $\mathrm{Ca}^{2+}, \mathrm{Hg}^{2+}$ ) seem not helpful. Apart from ions species, the DNA immobilization and conformation are also influenced by ionic strength [34], DNA concentration $[11,35]$ and competition effect among different valence ions [13, 33, 36]. Anyhow, the above-mentioned factors are still not fully understood, and the effects need to be further discussed.

In this paper, we combine the SFA and AFM techniques together to study the adsorption and nanomechanical properties of ss-DNA molecules on mica surface. Specially, we investigated the effects of ss-DNA concentrations on ss-DNA adsorption behaviors. The results indicate that $50 \mathrm{ng} / \mu \mathrm{l}$ is the lowest concentration that ss-DNA molecules are able to absorb and subsequently form a dense layer on mica. The adsorption structure of ss-DNA was further characterized with AFM. Besides, the desorption of the adsorbed DNA films is also observed by introducing monovalent salts into the gap buffer, which is mainly ascribed to the decreased ion correlation force.

\section{Materials and Methods}

\subsection{Materials}

The ss-DNA of thymine with 80 bases $\left.\left(5^{\prime} \text {-[TTTT }\right]_{20}-3^{\prime}\right)$, was purchased from Sangon Biotech Co, Ltd. (Shanghai). Cobalt chloride ( $>98 \%)$, sodium chloride $(>99.999 \%)$ and HEPES (>99.5\%) were purchased from Sigma-Aldrich. Muscovite ruby mica of grade 1 was supplied by S\&J Trading Inc. Buffer solution was prepared by adding $1 \mathrm{mmol} / \mathrm{L} \mathrm{CoCl}{ }_{2}$ or $\mathrm{NaCl}$ to $10 \mathrm{mmol} / \mathrm{L}$ HEPES buffer, then the mixture was titrated to $\mathrm{pH}$ 7.5. All solutions above contain $10 \mathrm{mmol} / \mathrm{L}$ HEPES, therefore the buffer solutions discussed below will be called by the cation species. Deionized water was used throughout. All the aqueous solutions were filtered through the Millipore filter with pore size of $0.22 \mu \mathrm{m}$ (Whatman). 


\subsection{Surface Preparation}

Mica sheets were mechanically cleaved to $3-5 \mu \mathrm{m}$ in a laminar cabinet, and cut into pieces of $\sim 1 \mathrm{~cm}^{2}$ with hot Pt wire [37]. Then the mica pieces were sputtered with a reflective silver layer of $\sim 50 \mathrm{~nm}$ to generate "fringes of equal chromatic order" (FECO) [38]. Afterwards, two mica sheets were glued (silver down) onto two cylindrical silica disks with epoxy resin (Shell, EPON 1004F), then stored in a vacuum desiccator for use.

The stock of $1000 \mathrm{ng} / \mu \mathrm{L}$ ss-DNA (Thymine) solution (10 mM Tris- $\mathrm{HCl}, 1 \mathrm{mM}$ EDTA, $\mathrm{pH}$ 7.5) was further diluted to the final concentrations $(10,25,50,100 \mathrm{ng} /$ $\mu \mathrm{L}$ ) with $1 \mathrm{mmol} / \mathrm{L} \mathrm{CoCl}$. A freshly cleaved mica sheet was rinsed with the buffer solution used in ss-DNA dilution. Then, $20 \mu \mathrm{l}$ diluted ss-DNA solution was dropped on the treated mica surface. After a 20-min incubation, the surface was flushed thoroughly with excessive buffer to remove unbound ss-DNA, and a droplet of buffer was left on mica surface. The DNA-coated disk was kept for use. Finally, two disks were mounted into apparatus in a cross-cylinder geometry. Each experiment was reproducibly repeated twice at least. During each experiment, the hardwall distance measured from three points far apart are nearly the same, implying uniform absorbed DNA layers.

\subsection{Instruments-SFA and AFM}

The SFA 2000 system (Surface LLC, Santa Barbara, CA) was used to investigate the adsorption behaviors of ssDNA on mica. More details of SFA were available in previous studies [39]. As shown in Figure 1, the absolute distance $D$ between two surfaces was measured from FECO at the angstrom resolution level [38]. The $D_{\mathrm{H}}$ represented hardwall, characterizing the thickness of adsorbed layers. Besides, the interaction between two surfaces were measured from the deformation of cantilever spring with certain stiffness. The adhesive energy between two flat surfaces could be acquired by JKR

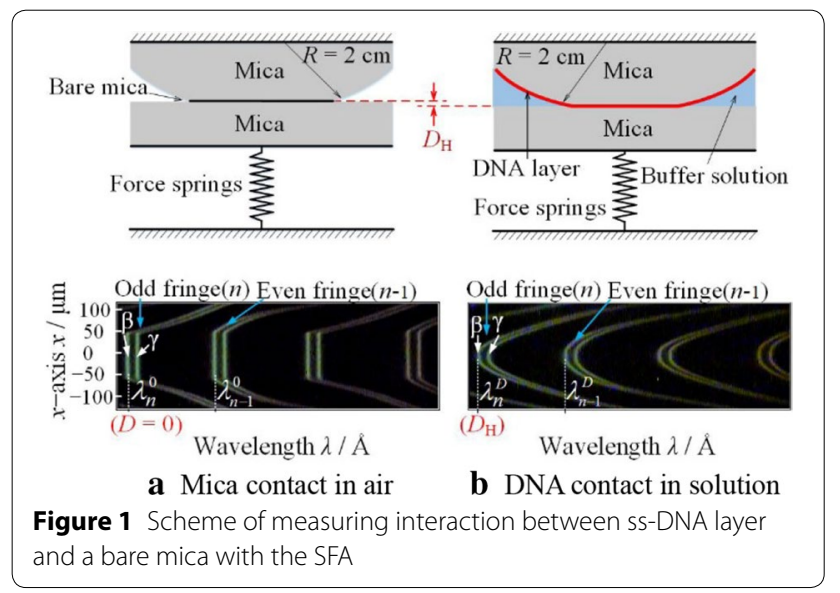

model $\left(E_{\mathrm{ad}}=F_{\mathrm{ad}} / 1.5 \pi R\right)$ for adhesive elastic contact, where $F_{\text {ad }}$ is the measured adhesive force and $R$ is the curvature radius of the surface.

The AFM used here is MFP 3D from Asylum Research. AFM images were obtained in tapping mode with silicon tips (spring constant is $2 \mathrm{~N} / \mathrm{m}$ and tip diameter is $20 \mathrm{~nm}$ ). The scan rate was typically $1 \mathrm{~Hz}$ per line and the modulation amplitude was about a few nanometer. The relative height (surface roughness) of the ss-DNA layers was measured by section analysis.

\section{Results and Discussion}

\subsection{Effect of ss-DNA Concentrations on ss-DNA Adsorption on Mica Surfaces}

To explore the lowest ss-DNA concentration that ssDNA can form a thin-layer on mica surface, ss-DNA were incubated in $1 \mathrm{mmol} / \mathrm{L} \mathrm{CoCl}$ solution with various ss-DNA concentrations. Figure 2(a) reveals the forcedistance profiles measured with SFA, where open symbols for in-run and solid symbols for out-run. A slight steric repulsion emerges and then hinders surfaces from approaching when two mica are driven into contact. With further approach, the profiles appear a vertical area where force increases rapidly but distance nearly keeps constant even under load beyond $15 \mathrm{mN} / \mathrm{m}$. In SFA experiment, such constant distance $D_{\mathrm{H}}$, typically defined as the hardwall distance, is used to characterize the

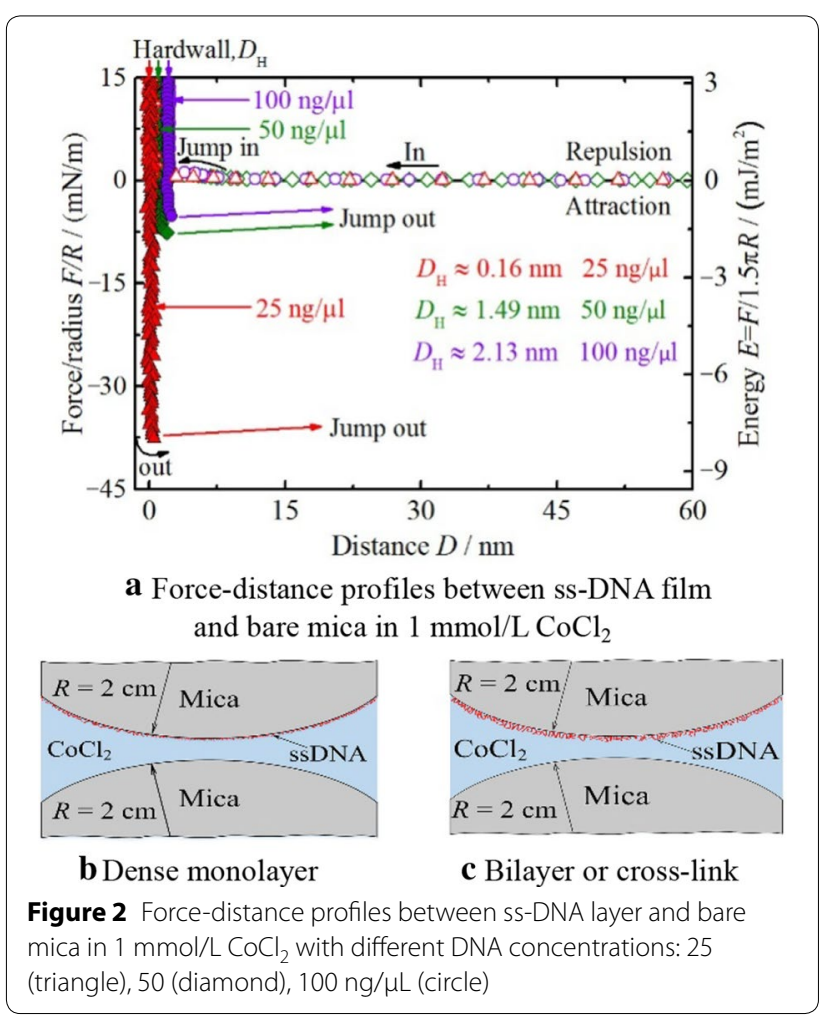


thickness of adsorbed layer on the substrate, as illustrated in Figure 1(b).

In the case of $25 \mathrm{ng} / \mu \mathrm{L}$, the average hardwall is $0.16 \pm 0.1 \mathrm{~nm}$, meaning few or no ss-DNA binds to mica within measurement error; As DNA concentration increases to $50 \mathrm{ng} / \mu \mathrm{L}$, the hardwall distance increases to $1.49 \pm 0.2 \mathrm{~nm}$. Considering the measured hardwall distance is equivalent to the dynamic diameter of ss-DNA molecules of 1.2-1.4 $\mathrm{nm}$ in solution [40], this hardwall presents a dense monolayer composed of ss-DNA molecules flat-lying on mica substrate, as illustrated in Figure 2(b). This is greatly consistent with the previous studies, revealing the formation of close-packed DNA monolayer on mica surface in $\mathrm{CoCl}_{2}$ solution containing various DNA $(\lambda$-DNA $[12,13]$, plasmid DNA [12, 35] or linear DNA [12]). As DNA concentration further increases to $100 \mathrm{ng} / \mu \mathrm{L}$, a larger hardwall distance of $2.13 \pm 0.2 \mathrm{~nm}$ implies an ordered ss-DNA bilayer or a cross-link configuration that DNA molecules cross or overlap each other, which is shown in Figure 2(c). The expected cross-link or condensation configuration of DNA on mica has been reported previously [12, 41], which further identify the above explanation about ssDNA geometry for $D_{\mathrm{H}}=2.13 \mathrm{~nm}$. These adsorptions are tight and stable enough due to the reproducible measurements even beyond $15 \mathrm{mN} / \mathrm{m}$.

In order to further demonstrate ss-DNA did adsorb on mica substrate, the adsorption structure of $100 \mathrm{ng} /$ $\mu \mathrm{L}$ ss-DNA on mica surface was further characterized with AFM, shown in Figure 3. The sample preparation is the same as before, except the sample was dried with N2 at last. It can be found that almost the whole mica surface is covered with condensed wormlike ss-DNA molecules. The surface roughness of adsorbed ss-DNA film is $\sim 1.8 \pm 0.2 \mathrm{~nm}$ in Figure 3(a), which was thought to be the relative height of adsorbed film from the mica surface, approximately corresponding to the hardwall distance measured in the previous SFA experiments.

Furthermore, Figure 3(c) reveals the roughness of mica surface is less than $0.15 \mathrm{~nm}$, which is smooth enough to be used as a substrate in DNA absorption investigations. However, after ss-DNA absorption illustrated in Figure 3(b), the mica surface becomes uneven and has a high and uniform surface coverage of ss-DNA. To sum up, these AFM results certifies the adsorption morphology and configuration of ss-DNA measured by SFA.

In addition to the difference in configuration, the nanomechanical properties are also presented in Figure 2(a). An adhesive force between DNA-coated mica and bare mica were measured during surface separation. "Jump in" phenomenon was found only at DNA concentration less than $50 \mathrm{ng} / \mu \mathrm{L}$ and "jump out" in all DNA conditions (note: jump in and jump out phenomenon occur in the

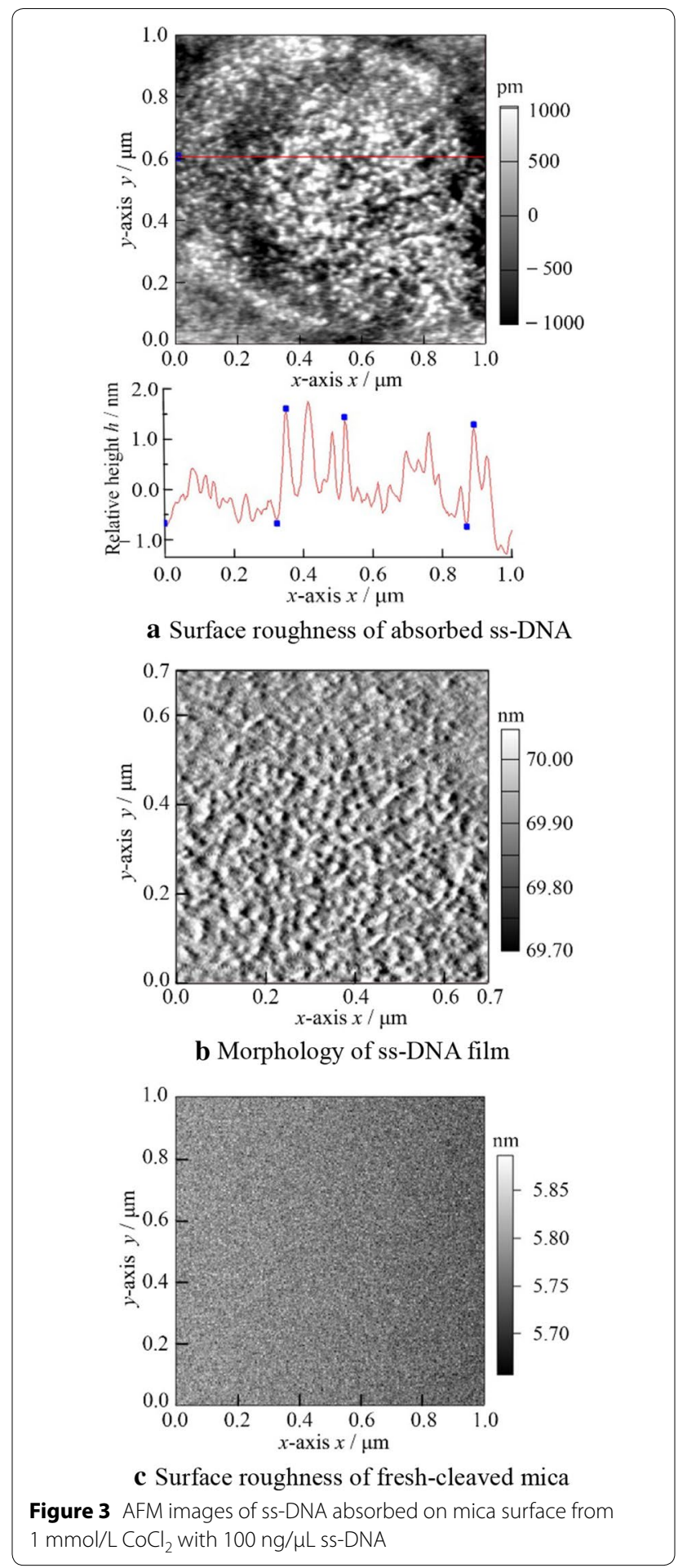

case of the interaction force larger than cantilever-spring force when surface approach and separation respectively). Under the condition of less than $25 \mathrm{ng} / \mu \mathrm{L}$ (data of $10 \mathrm{ng} / \mu \mathrm{L}$ not shown), the adhesion reaches $-37.5 \pm 0.2$ $\mathrm{mN} / \mathrm{m}$, which is six times higher than those at 50 and $100 \mathrm{ng} / \mu \mathrm{L}$. However, this value is roughly consistent with the force between two bare micas in the same solution 
(as discussed below), which further proved few or no ssDNA absorb on mica at $25 \mathrm{ng} / \mu \mathrm{L}$. Furthermore, the adhesive force decreases to $-6.5 \pm 0.2 \mathrm{mN} / \mathrm{m}\left(E_{\mathrm{ad}} \approx-1.38 \mathrm{~mJ} /\right.$ $\left.\mathrm{m}^{2}\right)$ at $50 \mathrm{ng} / \mu \mathrm{L}$ and $-5.3 \pm 0.2 \mathrm{mN} / \mathrm{m}\left(E_{\mathrm{ad}} \approx-1.12 \mathrm{~mJ} /\right.$ $\mathrm{m}^{2}$ ) at $100 \mathrm{ng} / \mu \mathrm{L}$, which are slightly higher than previous studies [13], perhaps due to different $\mathrm{CoCl}_{2}$ concentration. These adhesive forces far lower than those between two bare micas actually prove ss-DNA molecules have been assuredly immobilized on mica. Additionally, the adhesive force at $100 \mathrm{ng} / \mu \mathrm{L}$ is slightly less than $50 \mathrm{ng} / \mu \mathrm{L}$, which was due to the stronger steric effect induced by the more adsorbed ss-DNA.

Generally, the counterion-correlation effect is believed to be the dominant cause of dsDNA adsorption on mica mediated by divalent cations [12,33]. Therefore, it is also expected that ss-DNA molecules are capable to adsorb onto mica surface immersed in divalent cation solution with the sharing of the ss-DNA and mica counterions. In this case, divalent salt acts as bridge between ss-DNA and mica, thus producing a net attraction that pulls ssDNA onto mica surface. However, the measured force is greater than that of others who only ascribed adsorption to ion-correlation [33]. This is due to the cooperative effect of divalent metal ions condensation along DNA and their reaction with the surface groups [32]. The electrostatic potentials of DNA induce the increase of surface divalent ions concentration, which promotes the reaction of divalent ions with the surface and further results in the stronger ss-DNA adsorption.

\subsection{Desorption of ss-DNA from Mica Surface with Excessive Monovalent Counterion}

It is generally believed the competition effect between monovalent and divalent salts in solutions may result in the release of dsDNA molecules from mica surface $[27,33,35]$. In this study, the desorption behavior of absorbed ss-DNA layer from mica was observed by introducing monovalent salts into the gap buffer. As shown in Figure 4, once ss-DNA adsorption in $1 \mathrm{mmol} / \mathrm{L}$ $\mathrm{CoCl}_{2}$ (marked as Step 1), the gap buffer was completely replaced with excessive $1 \mathrm{mmol} / \mathrm{L} \mathrm{NaCl}$ (Step 2), finally the gap buffer was returned back to $1 \mathrm{mmol} / \mathrm{L} \mathrm{CoCl}_{2}$ (Step 3). The interaction between two surfaces in Step 1 is the same as that of Figure 2 at $50 \mathrm{ng} / \mu \mathrm{L}$ : the hardwall $(\sim 1.48 \mathrm{~nm})$ was equal to a monolayer as before shown in Figure 4(b).

It is intriguing to note that the measured hardwall changes dramatically in different Steps. The hardwall decreases sharply to $\sim 0.34 \mathrm{~nm}$ once the gap buffer was replaced to $\mathrm{NaCl}$ (Step 2 in Figure 4). Considering the measurement error, the sharp decrease in hardwall reveals desorption of ss-DNA layer from mica does occur in $1 \mathrm{mmol} / \mathrm{L} \mathrm{NaCl}$. Additionally, a long-range repulsion

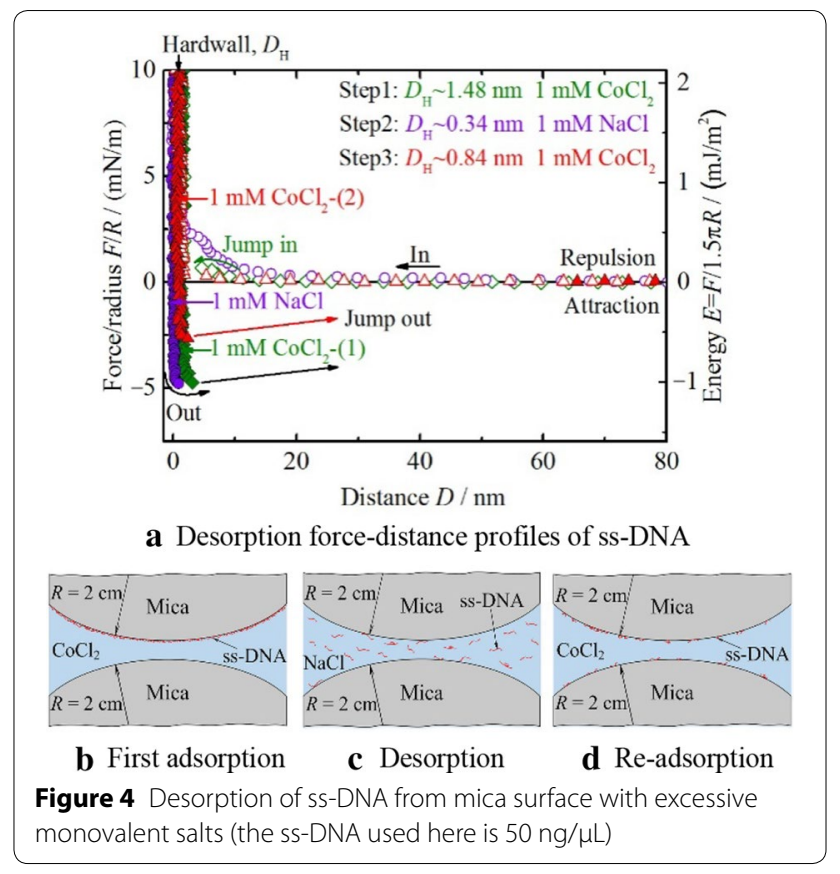

at a distance of $25 \pm 2 \mathrm{~nm}$ in Step 2 is observed in Figure 4(a), which is likely ascribed to the cooperative combination of double-layer force from electrolyte solution and steric repulsion induced by the released ss-DNA suspended in buffer solution shown in Figure 4(c). In the last step, the hardwall increases to $0.84 \pm 0.2 \mathrm{~nm}$, which is far less than that of Step 1. This none-zero hardwall may be due to that the residual ss-DNA in solutions immediately reabsorb onto mica surface once $\mathrm{CoCl}_{2}$ was added, as shown in Figure 4(d).

The desorption strength of ss-DNA is monitored by the binding competition between monovalent and divalent cations on mica surface. Based on Poisson-Boltzmann equation and site-binding model [42], if monovalent salts were added to the bulk solution containing divalent salts, the divalent and monovalent cations would compete fiercely with each other for the binding sites of mica surface and DNA, thus decreasing markedly the surface density of divalent cations, which directly weakens the binding strength of DNA molecules on mica surface [33]. Therefore, the loosely bound ss-DNA can be easily squeezed out in monovalent salts solution, thus resulting in the desorption of ss-DNA from mica surface.

In addition, the nano-mechanical properties were also measured for studying the desorption behavior of ssDNA thoroughly. In Step 1, the adhesive force $(-5 \pm 0.2$ $\mathrm{mN} / \mathrm{m}$ ) is consisted with that in Figure 2 within error. However, after the gap buffer was replaced by monovalent salts and returned back to divalent salts, an interesting feature is found in Step 3: the adhesion decreases to half of the original magnitude when the buffer was returned back, which may be due to that the binding sites 
of mica and DNA sites are occupied by $\mathrm{Na}^{+}$[33]. All in all, the above phenomenon implies the cobalt ions play a crucial role in binding energy between adsorbed monolayer and bare mica surface.

To further explore the desorption of ss-DNA, a control experiment between two bare mica surfaces was conducted in the same buffer solutions without ss-DNA. As shown in Figure 5, the hardwall is close to zero in both $\mathrm{CoCl}_{2}$ solution, but increases to $0.65 \mathrm{~nm}$ in $\mathrm{NaCl}$ solution, which is likely due to the hydration of $\mathrm{Na}^{+}$[43]. The experimental process is the same as the Steps of Figure 4, except no ss-DNA in the buffer solutions. As discussed above, the much higher adhesion in Step 1 than that of Figure 4 verifies ss-DNA absorption does occur. Comparing the Step 3 with Step 1, the force-distance profiles are almost the same: no long-range repulsion is found and two surfaces jump into contact from $\sim 5 \mathrm{~nm}$ due to van der Waals interaction. However, in Step 2, the long-range repulsion observed on approaching comes from the electrostatic double-layer force and the initial distance of repulsion: $\sim 10.6 \mathrm{~nm}$ is roughly equivalent to the theoretical Debye length: $9.6 \mathrm{~nm}$. In brief, this exploration further explains the effects of some factors (ion species, ion valence and DNA concentrations) on the ss-DNA desorption behaviors.

As we know, due to the competition effect, the decrease in surface concentration of divalent cations by adding monovalent salts will directly weaken the binding affinity of ss-DNA on mica substrate. Meanwhile, high surface density of monovalent cations also inhibits DNA from attracting to mica surface. Each of these is responsible for the reduction of ion-correlation effect, which is believed to be the dominant cause of ss-DNA adsorption. Therefore, the desorption of ss-DNA layer in monovalent salts solution is mainly ascribed to the reduced ion-ion

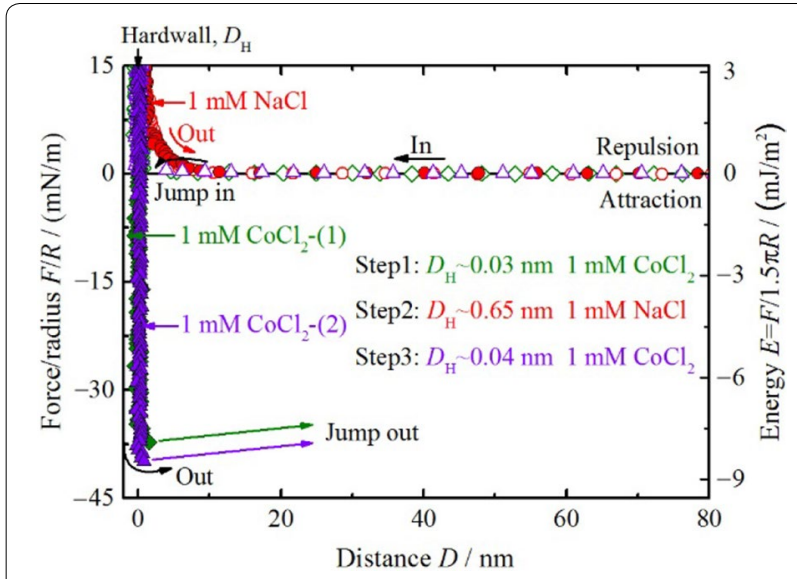

Figure 5 Force-distance profiles between two bare mica surfaces in certain buffer solution correlation force due to the sharp reduction of $\mathrm{Co}^{2+}$ surface concentration. Furthermore, $\mathrm{Na}^{+}$in buffer solution may occupy the binding sites on both mica surface and ss-DNA molecules, thus screening the binding sites for $\mathrm{Co}^{2+}$ binding to ss-DNA [35]. In this case, the loosely bound ss-DNA on mica surface can be easily squeezed out under high loads.

\section{Conclusions}

(1) The adsorption and desorption behaviors of ssDNA on mica substrate are studied by SFA technique. The ss-DNA concentrations exploration reveals $50 \mathrm{ng} / \mu \mathrm{L}$ is the lowest concentration for the formation of ss-DNA dense monolayer in divalent solution.

(2) ss-DNA present diverse morphology structures at different concentrations: lying flat on mica at $50 \mathrm{ng} /$ $\mu \mathrm{L}$, but forming bilayer or cross-link at $100 \mathrm{ng} / \mu \mathrm{L}$, and these structures are tight and stable enough. An attractive adhesion is measured simultaneously during separation, which is dominated by the correlation effect of divalent cations.

(3) The AFM morphology investigation show the entire surface is covered with condensed wormlike ssDNA molecules and the measured surface roughness $(\sim 1.8 \pm 0.2 \mathrm{~nm})$ proves the hardwall of SFA.

(4) The desorption behaviors of ss-DNA from mica occurs during introducing monovalent salts. It is the invalidation of ion-correlation effects due to sharp reduction of $\mathrm{Co}^{2+}$ surface concentration that induces the release of ss-DNA layer from mica. All results presented here can flexibly adjust the thickness of DNA film and improve the stability and mechanical ability of the film, which help to design and fabricate the DNA-based nano-devices in nanoscale.

Authors' Contributions

G-BS, Y-JK and M-HC conceived the research. G-BS and Y-JK designed the experiments. G-BS performed the experiments. G-BS, Y-JK and Y-FC analyzed the data. G-BS and Y-JK wrote the manuscript. All authors read and approved the final manuscript.

\section{Author Details \\ ${ }^{1}$ Jiangsu Key Laboratory for Design and Manufacture of Micro-Nano Bio- medical Instruments, Southeast University, Nanjing 211189, China. ${ }^{2}$ School of Mechanical Engineering, Southeast University, Nanjing 211189, China.}

\section{Authors' Information}

Gui-Bin Shen, born in 1991, is currently a master candidate at Jiangsu Key Laboratory for Design and Manufacture of Micro-Nano Biomedical Instruments, Southeast University, China and School of Mechanical Engineering, Southeast University, China. He received his bachelor degree from Southwest University of Science and Technology, China, in 2014. His research interests include biomaterial adhesion and the interaction between solid and liquid interface. 
Ya-Jing Kan, born in 1985, is currently a lecturer at School of Mechanical Engineering, Southeast University, China. He received his PhD degree from Southeast University, China, in 2015. His research interests include biological adhesion and the interactions between solid and liquid interface.

Min-Hua Chen, born in 1964, is currently an associate professor at School of Mechanical Engineering, Southeast University, China. Her research interests include nano technology and theory.

Yun-Fei Chen, born in 1967, is currently a professor, Cheung Kong Scholar, and PhD candidate supervisor at Jiangsu Key Laboratory for Design and Manufacture of Micro-Nano Biomedical Instruments, Southeast University, China and School of Mechanical Engineering, Southeast University, China. His main research interests include micro-nano tribology, heat transfer, fluid dynamics and micro-nano manufacture.

\section{Competing Interests}

The authors declare that they have no competing interests.

\section{Funding}

Supported by National Natural Science Foundation of China (Grant No. 51435003), and Jiangsu Provincial Natural Science Foundation of China (Grant No. BK20160670).

\section{Publisher's Note}

Springer Nature remains neutral with regard to jurisdictional claims in published maps and institutional affiliations.

\section{Received: 8 August 2016 Accepted: 25 September 2018}

Published online: 08 October 2018

\section{References}

[1] M R Jones, N C Seeman, C A Mirkin. Programmable materials and the nature of the DNA bond. Science, 2015, 347(6224): 1260901

[2] S Vellampatti, S B Mitta, J A Kim, et al. Streptavidin bound DNA open tube and $\mathrm{Zn}^{2+}$-doped DNA open lattice. Current Applied Physics, 2015, 15(8): $851-856$

[3] M L Yola, T Eren, N Atar. A novel and sensitive electrochemical DNA biosensor based on Fe@Au nanoparticles decorated graphene oxide. Electrochim Acta, 2014, 125: 38-47

[4] F Yan, H Tang. Application of thin-film transistors in label-free DNA biosensors. Expert Review of Molecular Diagnostics, 2014, 10(5): 547-549.

[5] T Liedl, T L Sobey, F C Simmel. DNA-based nanodevices. Nano Today, 2007, 2(2): 36-41.

[6] K M Horsman, J M Bienvenue, K R Blasier, et al. Forensic DNA analysis on microfluidic devices: a review. Journal of Forensic Sciences, 2007, 52(4): 784-799.

[7] C M Niemeyer. Functional devices from DNA and proteins. Nano Today, 2007, 2(2): 42-52.

[8] C Debouck, P N Goodfellow. DNA microarrays in drug discovery and development. Nature Genetics, 1999, 21: 48-50

[9] M Schena, D Shalon, RW Davis, et al. Quantitative monitoring of gene expression patterns with a complementary DNA microarray. Science, 1995, 270(5235): 467-470.

[10] S Surana, A R Shenoy, Y Krishnan. Designing DNA nanodevices for compatibility with the immune system of higher organisms. Nature Nanotechnology, 2015, 10(9): 741-747.

[11] L L Sun, D X Zhao, Y Zhang, et al. DNA adsorption and desorption on mica surface studied by atomic force microscopy. Applied Surface Science, 2011, 257(15): 6560-6567.

[12] Y H Song, C L Guo, L L Sun, et al. Effects of bridge ions, DNA species, and developing temperature on flat-lying DNA monolayers. The Journal of Physical Chemistry B, 2007, 111(2): 461-468.

[13] Y J Kan, Q Y Tan, G S Wu, et al. Study of DNA adsorption on mica surfaces using a surface force apparatus. Scientific Reports, 2015, 5: 8442

[14] J Adamcik, D V Klinov, G Witz, et al. Observation of single-stranded DNA on mica and highly oriented pyrolytic graphite by atomic force microscopy. FEBS Letters, 2006, 580(24): 5671-5675.
[15] S Bashar, S Kim, S U Hwang, et al. Coverage percentage and coverage rate of different DNA nanostructures grown on a mica substrate. Current Applied Physics, 2015, 15(11): 1358-1363.

[16] Z L Guo, Y W Wang, A Yang, et al. The effect of pH on charge inversion and condensation of DNA. Soft Matter, 2016, 12(31): 6669-6674.

[17] L S Shlyakhyenko, A A Gall, Y L Lyubchenko. Mica functionalization for imaging of DNA and protein-DNA complexes with atomic force microscopy. Methods in Molecular Biology, 2013, 931: 295-312.

[18] A F Raigoza, JW Dugger, L J Webb. Review: recent advances and current challenges in scanning probe microscopy of biomolecular surfaces and interfaces. ACS Applied Materials \& Interfaces, 2013, 5(19): 9249-9261.

[19] E Shapir, L Sagiv, N Borovok, et al. High-resolution STM imaging of novel single G4-DNA molecules. The Journal of Physical Chemistry B, 2008 , 112(31): 9267-9269.

[20] Y Y Cao, K Z Kao, CY Mou, et al. Oriented chiral DNA-Silica film guided by a natural mica substrate. Angewandte Chemie International Edition, 2016, 55(6): 2037-2041

[21] N A Cervantes, B Gutierrez. Robust deposition of lambda DNA on mica for imaging by AFM in air. Scanning, 2014, 36(6): 561-569.

[22] A Yacoot, L Koenders. Aspects of scanning force microscope probes and their effects on dimensional measurement. Journal of Physics D: Applied Physics, 2008, 41(10): 103001.

[23] E W Danner, Y Kan, M U Hammer, et al. Adhesion of mussel foot protein Mefp-5 to mica: an underwater superglue. Biochemistry, 2012, 51(33): 6511-6518.

[24] D J Billingsley, A J Lee, N A Johansson, et al. Patchiness of ion-exchanged mica revealed by DNA binding dynamics at short length scales. Nanotechnology, 2014, 25(2): 025704

[25] D Pastre, O Pietrement, A Zozime, et al. Study of the DNA/ethidium bromide interactions on mica surface by atomic force microscope: influence of the surface friction. Biopolymers, 2005, 77(1): 53-62.

[26] N H Thomson, S Kasas, B Smith, et al. Reversible binding of DNA to mica for AFM imaging. Langmuir, 1996, 12(24): 5905-5908.

[27] D Pastre, L Hamon, F Landousy, et al. Anionic polyelectrolyte adsorption on mica mediated by multivalent cations: a solution to DNA imaging by atomic force microscopy under high ionic strengths. Langmuir, 2006, 22(15): 6651-6660.

[28] H Zapletalová, J Přibyl, M Ambrož, et al. Improved method for Mica functionalization used in single molecule imaging of DNA with atomic force microscopy. Mediterranean Journal of Chemistry, 2016, 5(5): 589-598.

[29] H G Hansma, KJ Kim, D E Laney, et al. Properties of biomolecules measured from atomic force microscope images: a review. Journal of Structural Biology, 1997, 119(2): 99-108.

[30] F Pincet, E Perez, G Bryant, et al. Long-range attraction between nucleosides with short-range specificity: Direct measurements. Physical Review Letters, 1994, 73(20): 2780-2783.

[31] H G Hansma, D E Laney. DNA binding to mica correlates with cationic radius: assay by atomic force microscopy. Biophysical Journal, 1996, 70(4): 1933-1939.

[32] H Cheng, K Zhang, J A Libera, et al. Polynucleotide adsorption to negatively charged surfaces in divalent salt solutions. Biophysical Journal, 2006, 90(4): 1164-1174

[33] D Pastre, O Pirtrement, S Fusil, et al. Adsorption of DNA to mica mediated by divalent counterions: a theoretical and experimental study. Biophysical Journal, 2003, 85(4): 2507-2518.

[34] P E Vandeventer, J S Lin, T J Zwang, et al. Multiphasic DNA adsorption to silica surfaces under varying buffer, $\mathrm{pH}$, and ionic strength conditions. The Journal of Physical Chemistry B, 2012, 116(19): 5661-5670.

[35] M L Sushko, A L Shluger, C Rivetti. Simple model for DNA adsorption onto a mica surface in 1:1 and 2:1 electrolyte solutions. Langmuir, 2006, 22(18): $7678-7688$

[36] SW Chen, B Honig. Monovalent and divalent salt effects on electrostatic free energies defined by the nonlinear Poisson-Boltzmann equation: application to DNA binding reactions. The Journal of Physical Chemistry $B$, 1997, 101(44): 9113-9118.

[37] J N Israelachvili, N A Alcantar, N Maeda, et al. Preparing contaminationfree mica substrates for surface characterization, force measurements, and imaging. Langmuir, 2004, 20(9): 3616-3622.

[38] G T Zhao, D Cai, G S Wu, et al. A study of structure and properties of molecularly thin methanol film using the modified surface forces apparatus. Microscopy Research and Technique, 2014, 77(11): 851-856. 
[39] J Israelachvili, Y Min, M Akbulut, et al. Recent advances in the surface forces apparatus (SFA) technique. Reports on Progress in Physics, 2010, 73(3): 036601

[40] Y Goto, T Haga, I Yanagi, et al. Deceleration of single-stranded DNA passing through a nanopore using a nanometre-sized bead structure. Scientific Reports, 2015, 5: 16640.

[41] J G Duguid, V A Bloomfield. Aggregation of melted DNA by divalent metal ion-mediated cross-linking. Biophysical Journal, 1995, 69(6): 2642-2648.
[42] D E Yates, S Levine, TW Healy. Site-binding model of the electrical double layer at the oxide/water interface. Journal of the Chemical Society, Faraday Transactions 1: Physical Chemistry in Condensed Phases, 1974, 70: 1807-1818.

[43] G T Zhao, W C Guo, Q Y Tan, et al. Force measurement between mica surfaces in electrolyte solutions. Journal of Southeast University, 2013, 29(1): $57-61$.
Submit your manuscript to a SpringerOpen ${ }^{\bullet}$ journal and benefit from:

- Convenient online submission

- Rigorous peer review

- Open access: articles freely available online

- High visibility within the field

Retaining the copyright to your article

Submit your next manuscript at $\boldsymbol{\nabla}$ springeropen.com 